\title{
Pendeteksian lightning dan thunderstorm pada area ruang udara bandara Jog/Wahh Adisutjipto International Airport dan Yogyakarta International Airport
}

\author{
Indro Lukito*,1, Intan Dyah Pradnjaparamitha ${ }^{2}$, Bambang Sudibya ${ }^{3}$, \\ Denny Dermawan ${ }^{4}$ \\ ${ }^{1}$ Program Studi Teknik Dirgantara Sekolah Tinggi Teknologi Adisutjipto \\ ${ }^{2,3,4}$ Program Studi Teknik Elektro Sekolah Tinggi Teknologi Adisutjipto \\ Email Korespondensi: *lukito_dalbo@yahoo.com
}

\begin{abstract}
Daerah Istimewa Yogyakarta have Yogyakarta International Airport and Adisutjipto International Airport to serve both of civil and military flight mission. Airport must be supported by weather information system for the flight safety. One of any methodes to detect bad weather is using radiosonde to record weather moving in every step of atmospheric level. Using indexes of weather detection can predict the developing weather and presented thunderstorm, lightning and any storm in both of airport area. The significant weather such as thunderstorm and lightning shall be a big danger for the flight which are located $n$ its weather area and must avoid its area. The research focused to operating of radiosonde and how to analyze the becoming weather worst by calculating the weathar indexes of reported radiosonde recording. The result of its analyze is usefull for pilots especially in any steps of the flight, takeoff, approach and landing. Operating of radiosonde equipment which consist of ground equipment, antenna system, Global Positioning System, software of MGPS2, provided any transmission data that can be used to predict possibility bad weather and presented storm. The results of this research are lightning density in Weather Zone A Yogyakarta International Airport is $\quad d_{A}=17,97715$ lightning $/ \mathrm{km}^{2} . y r$ with lightning threat level classified as "MIDDLE". Lightning density in Weather Zone B Adisutjipto International Airport is $d_{B}=9,346163$ lightning $/ \mathrm{km}^{2} . y r$ with lightning threat level classified as "LOW". There were presented thunderstorm caused by high convection of heat in the atmosphere with possibility presented storm up to $75 \%$ in the bad weather condition.
\end{abstract}

Keywords: flight safety, radiosonde, thunderstorm, lightning

\section{Pendahuluan}

Faktor utama dalam penerbangan adalah keselamatan penerbangan. Keselamatan penerbangan didapatkan dari beberapa aspek penanganan yang bertujuan untuk menciptakan pesawat yang selamat tiba ditempat tujuan. Faktor-faktor penanganan tersebut yang terkait dengan tujuan keselamatan penerbangan (Flight Savety) adalah faktor teknik pesawat terbang, faktor operasi penerbangan, faktor pendukung operasional bandar udara, dan faktor cuaca. 
Faktor cuaca sebagai penentu yang signifikan bagi terciptanya keselamatan penerbangan. Beberapa aspek dari faktor cuaca adalah cuaca permukaan dan cuaca atmosfer. Batasan cuaca permukaan adalah batasan dimana kondisi cuaca yang terjadi pada saat pesawat untuk takeoff dan landing, serta saat climb dan approach sedangkan batasan cuaca atmosfer adalah kondisi dimana cuaca disuatu ketinggian terbang dimana pesawat melintas pada area cuaca tersebut. Jika batasan cuaca atmosfer menunjukan kondisi yang berbahaya saat dilintasi maka pesawat harus menghindari rute area cuaca tersebut dengan mengubah arah terbang atau mengubah ketinggian terbang.

Salah satu penyebab cuaca buruk di ketinggian terbang adalah keberadaan awan Cummolonimbus $(\mathrm{Cb})$ dimana saat awan tersebut pada posisi rendah potensi yang tampak terlihat adalah thuderstorm (Ts). Bentukan ini menghasilkan badai petir atau halilintar. Keberadaan awan tersebut membahayakan penerbangan dan harus dihindari.

Tingginya frekuensi penerbangan berdampak pada terjadinya antrian pesawat khususnya di area udara Yogyakarta International Airport (YIA) dan Adisutjipto International Airport (JOG). Saat pesawat akan melakukan antri pendaratan (holding) diupayakan untuk pada area dimana tidak terdapat atau jarang terjadi potensi terbentuknya awan cummolonimbus.

Penerbang memerlukan informasi cuaca pada setiap tahapan terbangnya (takeoff, climb, cruise, approach, landing). Sistim informasi tentang cuaca haruslah tepat, terkini dengan keakuratan yang maksimal. Beberapa metode dilakukan untuk mendapatkan informasi cuaca dari alam mulai dari pengamatan langsung secara visual, pengamatan dengan menggunakan peralatan meteorology, dalam bentuk data dan selanjutnya dilakukan analisis prakiraan cuaca ke depan. Informasi dan hasil pengamatan akurat bagi penerbang sebagai salah satu preventif terhadap gangguan keselamatan penerbangan.

\section{Metode Penelitian}

Dalam penelitian ini doilakukan observasi pada beberapa lokasi pengamatan baik di area udara JOG dan YIA serta menggunakan informasi data hasil pengamatan radiosonde oleh BMKG pada tiap level ketinggian atmosfer hingga 54.000 feet serta data weather forecasting dan upper wind chart dari aerodrome meteorological office kedua bandar udara. Selanjutnya hasil pengamatan dan data radiosonde hasil observasi menggunakan metode SWEAT dengan beberapa tahapan analisis berupa: (a) Indeks Kestabilan Awan, (b) Showalter Stability Index (SSI), (c) Lifted Index (LI), (d) K Index (KI), (e) Total Total Index (TTI), dengan pendekatan formula formula:

$$
\begin{aligned}
& \mathrm{SSI}=\mathrm{T}-\mathrm{T}^{\prime} \\
& \mathrm{LI}=\mathrm{T}_{500}-\mathrm{T}_{\mathrm{p}_{500}} \\
& \mathrm{KI}=\left(\mathrm{t}_{850}-\mathrm{t}_{500}\right)+\mathrm{t}_{\mathrm{d}_{850}}-\left(\mathrm{t}_{700}-\mathrm{t}_{\mathrm{d}_{700}}\right) \\
& \text { TTI }=\left(\mathrm{t}_{850}-\mathrm{t}_{500}\right)+\left(\mathrm{t}_{\mathrm{d}_{850}}-\mathrm{t}_{500}\right) \text {.... } \\
& \text { SWEAT }=12 \mathrm{td}_{850}+20(\mathrm{TTI}-49)+2 \mathrm{~F}_{850}+\mathrm{F}_{500}+125(\mathrm{~s}+0,2)
\end{aligned}
$$

Dan penghiutungan tekanan pada masing masing ketinggian atmosfer menggunakan pendekatan

$$
P=P_{b} x\left[\frac{T_{b}}{T_{b}+L_{b} x\left(h-h_{0}\right)}\right]^{\frac{g_{0} \times M}{R^{*} \times L_{b}}}
$$

Proses penelitian sebagai berikut: 


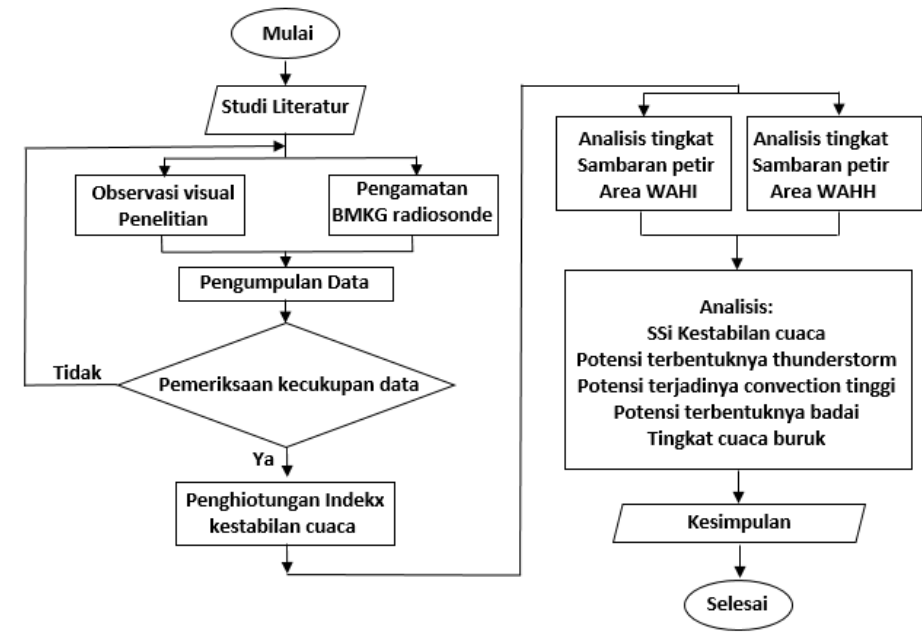

Gambar 1. Metode penelitian

Data yang diperlukan untuk melakukan analisis ini adalah:

Tabel 1. Static Pressure and Temperature Standard Lapse Rate

\begin{tabular}{|c|c|c|c|c|c|c|c|}
\hline \multirow{2}{*}{ Subscript $b$} & \multicolumn{2}{|c|}{ Height above sea level } & \multicolumn{2}{|c|}{ Static pressure } & \multirow{2}{*}{$\begin{array}{l}\text { Standard temperature } \\
\text { (K) }\end{array}$} & \multicolumn{2}{|c|}{ Temperature lapse rate } \\
\hline & (m) & (ft) & (pascals) & (inHg) & & $(\mathrm{K} / \mathrm{m})$ & $(\mathrm{K} / \mathrm{ft})$ \\
\hline 0 & 0 & 0 & 101325.00 & 29.92126 & 288.15 & -0.0065 & -0.0019812 \\
\hline 1 & 11,000 & 36,089 & 22632.10 & 6.683245 & 216.65 & 0.0 & 0.0 \\
\hline 2 & 20,000 & 65,617 & 5474.89 & 1.616734 & 216.65 & 0.001 & 0.0003048 \\
\hline 3 & 32,000 & 104,987 & 868.02 & 0.2563258 & 228.65 & 0.0028 & 0.00085344 \\
\hline 4 & 47,000 & 154,199 & 110.91 & 0.0327506 & 270.65 & 0.0 & 0.0 \\
\hline 5 & 51,000 & 167,323 & 66.94 & 0.01976704 & 270.65 & -0.0028 & -0.00085344 \\
\hline 6 & 71,000 & 232,940 & 3.96 & 0.00116833 & 214.65 & -0.002 & -0.0006096 \\
\hline
\end{tabular}

Tabel 2. Data Weather Forecasting

\begin{tabular}{|c|}
\hline TAFOR WAHI Yogyakarta International Airport \\
\hline 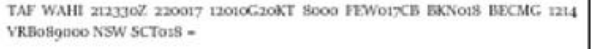 \\
\hline 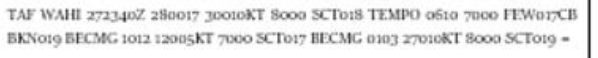 \\
\hline 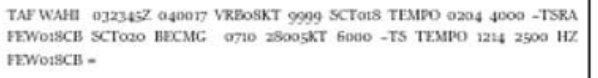 \\
\hline 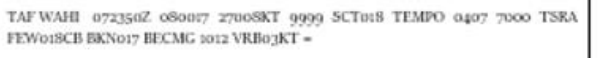 \\
\hline 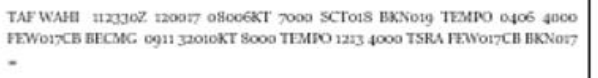 \\
\hline 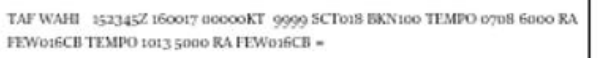 \\
\hline 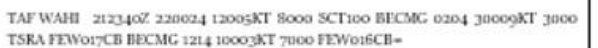 \\
\hline
\end{tabular}

TAFOR WAHH Yogyakarta International Airport

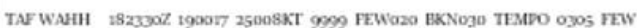

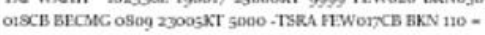

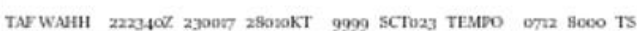
ПEWYO20CB EECMG 1315 22003KT 7000 -

TNF WAHH 282320\%Z 200057 300tokT B000 SCTa20 TFMPO 0610 4000 TSRA

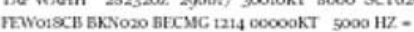

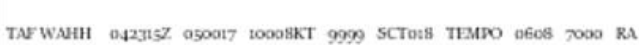

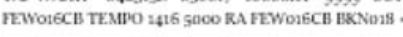

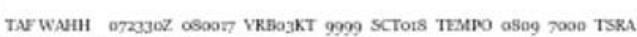

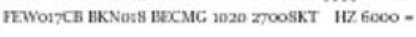

TAFWNH 152340Z 261858 34005KT 9999 SCTO18 TEMDO $03056000 \mathrm{RA}$ FEWOLECB EECMG O911 0400SKT TEMPO 1214 7000 RA FEWO17CB-

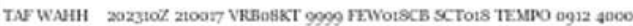
TSRA VEWO15CB BECMC 416 COOOnKT HZ FEWO16CB -

Tabel 3. Hasil Observasi BMKG 


\begin{tabular}{|c|c|c|c|c|c|c|c|c|c|c|c|c|}
\hline $\begin{array}{l}\text { WAHH } \\
\text { Atmosph }\end{array}$ & $\begin{array}{l}02.00 \mathrm{z} \\
\text { fic level }\end{array}$ & $\begin{array}{l}2019.12 .19 \\
\text { Sea Level tem }\end{array}$ & erature & $23,9{ }^{\circ} \mathrm{C}$ & & & & & & & & \\
\hline 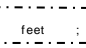 & 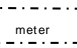 & 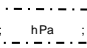 & & & & & & &. & & & crs \\
\hline $1.000,00$ & 304,88 & 955,72 & 2,20 ; & 21,70 & 34,02 & 19,69 & 34,00 & 294,85 & 296,21 & 292,84 & 18,00 & \\
\hline $2.000,00$ & 609,76 & 913,40 & 2,21； & 19,48 & 33,99 & 17,53 & 33,98 & 292,63 & 294,41 & 290,68 & 22,00 & 23,0 \\
\hline $3.000,00$ & 914,63 & 872,95 & 2,21； & 17,27 & 33,97 & 15,07 & 33,95 & 290,42 & 292,74 & 288,22 & 24,00 & 26,0 \\
\hline $4.000,00$ & $1.219,51$ & 834,30 & 2,27; & 14,82 & 33,95 & 12,72 & 33,93 & 287,97 & 291,01 & 285,87 & 21,00 & \\
\hline $5.000,00$ & $1.524,39$ & 797,36 & 2,23; & 12,75 & 33,93 & 11,66 & 33,92 & 285,90 & 289,02 & 284,81 & 16,00 & 22,0 \\
\hline $6.000,00$ & $1.829,27$ & 762,05 & 2,26 ; & 10,34 & 33,90 & 8,92 & 33,89 & 283,49 & 285,67 & 282,07 & 17,00 & 18,0 \\
\hline $7.000,00$ & $2.134,15$ & 728,30 & 2,25 ; & 8,15 & 33,88 & 7,96 & 33,88 & 281,30 & 283,55 & 281,11 & 17,00 & 19, \\
\hline $8.000,00$ & $2.439,02$ & 696,06 & 2,29; & 5,58 & 33,86 & 5,28 & 33,85 & 278,73 & 281,07 & 278,43 & 23,00 & 18,00 \\
\hline $9.000,00$ & $2.743,90$ & 665,23 & 2,27; & 3,47 & 33,83 & 5,37 & 33,85 & 276,62 & 278,80 & 278,52 & 26,00 & 26,00 \\
\hline $10.000,00$ & $3.048,78$ & 635,78 & 2,20 ; & 1,90 & 33,82 & 2,94 & 33,83 & 275,05 & 277,50 & 276,09 & 24,00 & 18,00 \\
\hline $1.000,00$ & $3.353,66$ & 607,62 & 2,25; & $(0,85)$; & 33,79 & 1,55 & 33,82 & 272,30 & 274,64 & 274,70 & 22,00 & 19,00 \\
\hline $2.000,00$ & $3.658,54$ & 580,72 & 2,23; & $(2,86)$ : & 33,77 & 0,37 & 33,80 & 270,29 & 272,67 & 273,52 & 18,00 & 18,00 \\
\hline $3.000,00$ & $3.963,41$ & 555,00 & 2,21; ; & $(4,83)$; & 33,75 & $(1,45)$; & 33,79 & 268,32 & 270,49 & 271,70 & 18,00 & 18,00 \\
\hline $4.000,00$ & $4.268,29$ & 530,43 & 2,22； & $(7,18)$ : & 33,73 & $(4,04)$; & 33,76 & 265,97 & 268,33 & 269,11 & 19,00 & 19,00 \\
\hline $5.000,00$ & $4.573,17$ & 506,94 & 2,20 ; & $(9,10)$; & 33,71 & $(4,70)$; & 33,75 & 264,05 & 266,29 & 268,45 & 20,00 & 18,00 \\
\hline $6.000,00$ & $4.878,05$ & 484,49 & 2,29; & $(12,74)$ : & 33,67 & $(8,27)$; & 33,72 & 260,41 & 262,60 & 264,88 & 24,00 & 21,00 \\
\hline $7.000,00$ & $5.182,93$ & 463,04 & 2,26 & $(14,52)$; & 33,65 & $(10,58)$; & 33,69 & 258,63 & 261,04 & 262,57 & 23,00 & 23,00 \\
\hline $8.000,00$ & $5.487,80$ & 442,54 & 2,23 ; & $(16,24)$; & 33,64 & $(13,01)$; & 33,67 & 256,91 & 259,19 & 260,14 & 22,00 & 18,00 \\
\hline $9.000,00$ & $5.792,68$ & 422,94 & 2,22 ; & $(18,28)$; & 33,62 & $(15,09)$; & 33,65 & 254,87 & 257,25 & 258,06 & 25,00 & 19,00 \\
\hline $20.000,00$ & $6.097,56$ & 40 & 2,27 & $(21,50)$; & 33,59 & (18,42): & 33,62 & 251,65 & 254,02 & 254,73 & 18,00 & 18,00 \\
\hline $1.000,00$ & $6.402,44$ & 386,31 & 2,26 ; & $(23,56)$ : & 33,56 & 20,54); & 33,59 & 249,59 & 251,91 & 252,61 & 28,00 & 23,00 \\
\hline $2.000,00$ & $6.707,32$ & 369,21 & 2,$29 ;$ & (26,48) : & 33,54 & $(23,13)$; & 33,57 & 246,67 & 248,86 & 250,02 & 19,00 & 23,00 \\
\hline $3.000,00$ & $7.012,20$ & & 2,$25 ;$ & $(27,85)$ : & & 25,8 & & & & & & \\
\hline $4.000,00$ & $7.317,07$ & 337,23 & 2,20 ; & $(28,90)$ : & 33,51 & $27,32)$; & 33,53 & 244,25 & 246,66 & 245,83 & 21,00 & 23,00 \\
\hline $5.000,00$ & $7.621,95$ & 322,30 & 2,21; & $(31,35)$; & 33,49 & $(29,30)$; & 33,51: & 241,80 & 244,08 & 243,85 & 23,00 & 12,00 \\
\hline $.000,00$ & $7.926,83$ & & 2,21; & $(33,56)$; & 33,46 & $(31,46)$; & 33,49 & & 241,78 & & 18,00 & , 00 \\
\hline $7.000,00$ & $8.231,71$ & 294,39 & 2,28 & $(37,66)$; & 33,42 & $35,18)$; & 33,45 & 235,49 & 237,90 & 237,97 & 19,00 & 17,00 \\
\hline $8.000,00$ & $8.536,59$ & 281,35 & 2,24; & $(38,82)$; & 33,41 & $(36,45)$; & 33,$44 ;$ & 234,33 & 236,61 & 236,70 & 21,00 & 25,00 \\
\hline 000,00 & 41,46 & & 2,23 ; & $0,77)$ : & 33,39 & $(38,38)$ & & & 2 & & 19,00 & ,00 \\
\hline $0.000,00$ & $9.146,34$ & 256,99 & 2,$26 ;$ & $(43,90)$ : & 33,36 & $(42,70)$; & 33,37 & 229,25 & 228,88 & 230,45 & 18,00 & 21,00 \\
\hline $1.000,00$ & $9.451,22$ & 245,61 & 2,21； & $(44,61)$ : & 33,35 & $(43,17)$; & 33,37 & 228,54 & 228,22 & 229,98 & 25,00 & 19,00 \\
\hline $.000,00$ & $9.756,10$ & & 2,20 & $(46,50)$; & 33,34 & $(45,72)$; & & & 227, & 7,43 & 28,00 & 8,00 \\
\hline $1.000,00$ & $10.060,98$ & 224,34 & 2,23 & $(49,69)$; & 33,30 & $50,07)$; & 33,30 & 223,46 & 224,90 & 223,08 & 23,00 & 25,00 \\
\hline $4.000,00$ & $10.365,85$ & 214,41 & 2,26 ; & $(52,94)$ : & 33,27 & 52,99) ; & 33,27 & 220,21 & 221,31 & 220,16 & 23,00 & 28,00 \\
\hline 000,00 & 70,73 & & 2,2 & & & & & & & 217,26 & 28,00 & 3,00 \\
\hline $5.000,00$ & $10.975,61$ & 195,84 & 2,$20 ;$ & $(55,30)$ : & 33,25 & 56,40) ; & 33,24 & 217,85 & 218,96 & 216,75 & 29,00 & 23,00 \\
\hline $.000,00$ & $11.280,49$ & 187,17 & 2,20 ; & (57,50) : & 33,23 & (58,68); & 33,21 & 215,65 & 216,97 & 214,47 & 23,00 & 21,00 \\
\hline 00,00 & 85,37 & & 2,2 & & & & & & & 2,17 & 24,00 & 4,00 \\
\hline $.000,00$ & $11.890,24$ & 170,96 & 2,20 & 1,90): & 33,18 & 63,15); & & 211,25 & 212,44 & 210,00 & 21,00 & 28,00 \\
\hline $.000,00$ & 195,12 & 163,39 & 2,20 & $(64,10)$; & 33,16 & 65,34) ; & 33,15 & 209,05 & 210,26 & 207,81 & 19,00 & 29,00 \\
\hline 0,00 & 00,00 & & 2,2 & & & & & & & & 8, & 3,00 \\
\hline $2.000,00$ & $.804,88$ & 9,24 & 2,2 & & 33 & 5) ; & & 204,65 & 206,09 & 203,4 & 25,00 & 24,00 \\
\hline $3.000,00$ & 109,76 & 142,6 & 2,20 & $(70,70)$ : & 33 & (71,97) ; & 33,08 & 202,4 & 203,67 & 01,18 & 28,00 & 21,00 \\
\hline & & & & & & & & & & & 0 & 8,00 \\
\hline & & & 2,27 & & & & & & 10 & 1. & 23, & 17,00 \\
\hline $6.0000,00$ & $14.024,39$ & 124,51 & 2,28 ; & $(80,98)$; & 32,99 & $(82,31) ;$ & 32,98 & 192,17 & 193,45 & 190,84 & 25,00 & 26,00 \\
\hline & & & & & & & & & & & 10 & 5,00 \\
\hline & & & & & & & & & & & & 2,00 \\
\hline 0000,00 & $14.939,02$ & 108,69 & 2,$29 ;$ & $(88,31)$ : & 32,92 & 9,51); & 32,90 & 184,84 & 186,13 & 183,64 & 27,00 & 25,00 \\
\hline & & 103. & & & & & & & & & & 3,00 \\
\hline & & & & & & & & & & & & 8,00 \\
\hline 0000,00 & $15.853,66$ & 94,8 & 2,24 & (9 & 32,87 & ); & 32,86 & 180,57 & 181,89 & 179,48 & 7,00 & 27,00 \\
\hline & & 90, & & & & & & & & 7,6 & & 9,00 \\
\hline & & & & & & & & & & & & \\
\hline
\end{tabular}


Tabel 4. Data Weather Presentation

WEATHER PRESENTATION January 2019

\begin{tabular}{|c|c|c|c|c|c|c|c|c|c|c|c|c|c|c|c|c|}
\hline \multirow{4}{*}{ Day } & \multicolumn{9}{|c|}{ Cloud Presentation } & \multirow{3}{*}{\multicolumn{3}{|c|}{$\begin{array}{c}\text { Significant Weather } \\
\text { Presentation } \\
\%\end{array}$}} & \multicolumn{2}{|c|}{ Weather Zone A } & \multicolumn{2}{|c|}{ Weather Zone B } \\
\hline & \multicolumn{3}{|c|}{ Low } & \multicolumn{3}{|c|}{ Middle } & \multicolumn{3}{|c|}{ High } & & & & \multirow{3}{*}{ CB Density } & \multirow{3}{*}{$\begin{array}{l}\text { Presented } \\
\text { lightning }\end{array}$} & \multirow{3}{*}{ CB Density } & \multirow{3}{*}{$\begin{array}{c}\text { Presented } \\
\text { Lighning }\end{array}$} \\
\hline & \multirow{2}{*}{ Dens } & \multirow{2}{*}{ kind } & \multirow{2}{*}{$\begin{array}{c}\text { heigh } \\
\text { feet }\end{array}$} & \multirow{2}{*}{ Dens } & \multirow{2}{*}{ kind } & \multirow{2}{*}{$\begin{array}{l}\text { heigh } \\
\text { feet }\end{array}$} & \multirow{2}{*}{ Dens } & \multirow{2}{*}{ kind } & \multirow{2}{*}{\begin{tabular}{|c|} 
heigh \\
feet \\
\end{tabular}} & & & & & & & \\
\hline & & & & & & & & & & TS & $\mathrm{RA}$ & Ice & & & & \\
\hline 1 & Scatter & Cu Sc Cb & 1450 & Scatter & $\mathrm{AcAs} \mathrm{Cb}$ & 7600 & Scatter & $\mathrm{CiCsCb}$ & 22000 & 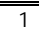 & 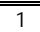 & 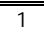 & Frequent & 70 & Occasional & 190 \\
\hline 2 & Broken & $\mathrm{CuScCb}$ & 1660 & Broken & $\mathrm{AcAsCb}$ & 7500 & Scatter & $\mathrm{CiCsCb}$ & 22500 & 1 & 0 & 1 & Occasional & 98 & Frequent & 22 \\
\hline 3 & Scatter & $\mathrm{Cu} \mathrm{ScCb}$ & 1540 & Scatter & $\mathrm{AcAs} \mathrm{Cb}$ & 8300 & Scatter & $\mathrm{CiCsCb}$ & 21600 & 1 & 1 & 1 & Isolated & 104 & Isolated & 25 \\
\hline 4 & Scatter & $\mathrm{Cu} \mathrm{ScCb}$ & 1800 & Scatter & $\mathrm{AcAs} \mathrm{Cb}$ & 8500 & Scatter & $\mathrm{CiCs} C b$ & 23000 & 1 & 1 & 1 & Occasional & 29 & Isolated & 14 \\
\hline 5 & Few & $\mathrm{CuScCb}$ & 1700 & Scatter & $\mathrm{AcAs} \mathrm{Cb}$ & 10500 & Scatter & $\mathrm{CiCsCb}$ & 25000 & 1 & 1 & 1 & Isolated & 118 & Occasional & 23 \\
\hline 6 & Scatter & $\mathrm{Cu} \mathrm{ScCb}$ & 1800 & Scatter & $\mathrm{AcAs} \mathrm{Cb}$ & 7500 & Scatter & $\mathrm{CiCsCb}$ & 24500 & 1 & 0 & 1 & Isolated & 190 & Occasional & 22 \\
\hline 7 & Scatter & $\mathrm{CuSc} \mathrm{Cb}$ & 1800 & Scatter & $\mathrm{AcAs} \mathrm{Cb}$ & 8000 & Scatter & $\mathrm{CiCsCb}$ & 24000 & 0 & 1 & 1 & Occasional & 0 & Isolated & 0 \\
\hline 8 & Broken & $\mathrm{Cu} \mathrm{ScCb}$ & 1700 & Scatter & $\mathrm{AcAs} \mathrm{Cb}$ & 8500 & Scatter & $\mathrm{CiCs} \mathrm{Cb}$ & 23000 & 1 & 1 & 1 & Isolated & 98 & Isolated & 26 \\
\hline 9 & Scatter & $\mathrm{CuScCb}$ & 1700 & Scatter & $\mathrm{AcAs} \mathrm{Cb}$ & 7500 & Scatter & $\mathrm{CiCsCb}$ & 24000 & 1 & 1 & 1 & Occasional & 116 & Occasional & 121 \\
\hline 10 & Scatter & $\mathrm{Cu} \mathrm{ScCb}$ & 1450 & Scatter & $\mathrm{AcAs} \mathrm{Cb}$ & 9000 & Scatter & $\mathrm{CiCsCb}$ & 26000 & 0 & 1 & 1 & Occasional & 0 & Isolated & 0 \\
\hline 11 & Scatter & $\mathrm{CuScCb}$ & 1450 & Scatter & $\mathrm{AcAs} \mathrm{Cb}$ & 7000 & Scatter & $\mathrm{CiCsCb}$ & 24000 & 1 & 0 & 1 & \begin{tabular}{|l|l} 
Isolated \\
\end{tabular} & 22 & Occasional & 176 \\
\hline 12 & Broken & $\mathrm{CuSc} \mathrm{Cb}$ & 1450 & Scatter & $\mathrm{AcAs} \mathrm{Cb}$ & 7500 & Scatter & $\mathrm{CiCsCb}$ & 22000 & 1 & & 1 & Occasional & 28 & Occasional & 22 \\
\hline 13 & Scatter & $\mathrm{Cu} \mathrm{ScCb}$ & 1800 & Scatter & $\mathrm{AcAs} \mathrm{Cb}$ & 8500 & Scatter & $\mathrm{CiCsCb}$ & 23000 & 0 & & 0 & Occasional & 0 & Isolated & 0 \\
\hline 14 & Few & $\mathrm{CuSc} \mathrm{Cb}$ & 1700 & Scatter & $\mathrm{Ac} \mathrm{As} \mathrm{Cb}$ & 10500 & Scatter & $\mathrm{CiCs} \mathrm{Cb}$ & 25000 & 1 & & 1 & ated & 148 & ional & 23 \\
\hline 15 & Scatter & $\mathrm{CuSc} \mathrm{Cb}$ & 1800 & Scatter & $\mathrm{Ac} \mathrm{As} \mathrm{Cb}$ & 7500 & Scatter & $\mathrm{CiCsCb}$ & 24500 & 1 & & 1 & Isolated & 79 & ional & 105 \\
\hline 16 & Scatter & $\mathrm{Cu} \mathrm{ScCb}$ & 1800 & Scatter & $\mathrm{AcAs} \mathrm{Cb}$ & 8500 & Scatter & $\mathrm{CiCsCb}$ & 23000 & 1 & & 1 & Occasional & 98 & Isolated & 65 \\
\hline 17 & Few & $\mathrm{Cu} \mathrm{ScCb}$ & 1700 & Scatter & $\mathrm{AcAs} \mathrm{Cb}$ & 10500 & Scatter & $\mathrm{CiCsCb}$ & 25000 & 0 & & 0 & Isolated & 0 & Occasional & 0 \\
\hline 18 & Few & $\mathrm{CuSc} \mathrm{Cb}$ & 1700 & Scatter & $\mathrm{AcAs} \mathrm{Cb}$ & 10500 & Scatter & $\mathrm{CiCsCb}$ & 25000 & 1 & & 1 & Isolated & 174 & Occasional & 33 \\
\hline 19 & Few & $\mathrm{CuSc} \mathrm{Cb}$ & 1700 & Scatter & $\mathrm{AcAs} \mathrm{Cb}$ & 10500 & Scatter & $\mathrm{CiCs} \mathrm{Cb}$ & 25000 & 1 & & 1 & Occasional & 92 & Occasional & 23 \\
\hline 20 & Scatter & $\mathrm{Cu} \mathrm{ScCb}$ & 1800 & Scatter & $\mathrm{AcAs} \mathrm{Cb}$ & 7500 & Scatter & $\mathrm{CiCsCb}$ & 24500 & 1 & & 1 & Isolated & 2 & Occasional & 45 \\
\hline 21 & Few & $\mathrm{AScCb}$ & 1700 & Scatter & $\mathrm{AcAs} \mathrm{Cb}$ & 10500 & Scatter & $\mathrm{CiCsCb}$ & 25000 & 1 & 1 & 1 & Isolated & 28 & \begin{tabular}{|l|} 
Occasional \\
\end{tabular} & 65 \\
\hline 22 & Scatter & $\mathrm{Cu} \mathrm{ScCb}$ & 1800 & Scatter & $\mathrm{AcAs} \mathrm{Cb}$ & 7500 & Scatter & $\mathrm{CiCsCb}$ & 24500 & 1 & 1 & 1 & Isolated & 25 & Occasional & 180 \\
\hline 23 & Scatter & $\mathrm{Cu} \mathrm{Sc} \mathrm{Cb}$ & 1800 & Scatter & $\mathrm{AcAs} \mathrm{Cb}$ & 8000 & Scatter & $\mathrm{CiCsCb}$ & 24000 & 1 & 1 & 1 & Occasional & 28 & Isolated & 19 \\
\hline 24 & Few & $\mathrm{Cu} \mathrm{ScCb}$ & 1700 & Scatter & $\mathrm{AcAs} \mathrm{Cb}$ & 10500 & Scatter & $\mathrm{CiCsCb}$ & 25000 & 1 & 1 & 1 & Isolated & 129 & Occasional & 23 \\
\hline 25 & Scatter & $\mathrm{Cu} \mathrm{Sc} \mathrm{Cb}$ & 1800 & Scatter & $\mathrm{AcAs} \mathrm{Cb}$ & 7500 & Scatter & $\mathrm{CiCs} \mathrm{Cb}$ & 24500 & 0 & 1 & 1 & Isolated & 0 & Occasional & 19 \\
\hline 26 & Scatter & $\mathrm{Cu} \mathrm{ScCb}$ & 1800 & Scatter & $\mathrm{AcAs} \mathrm{Cb}$ & 8000 & Scatter & $\mathrm{CiCsCb}$ & 24000 & 1 & 1 & 1 & Occasional & 89 & Isolated & 85 \\
\hline 27 & Broken & $\mathrm{Cu} \mathrm{ScCb}$ & 1700 & Scatter & $\mathrm{AcAs} \mathrm{Cb}$ & 8500 & Scatter & $\mathrm{CiCs} \mathrm{Cb}$ & 23000 & 1 & 1 & 1 & Isolated & 56 & Isolated & 175 \\
\hline 28 & Scatter & $\mathrm{CuSc} \mathrm{Cb}$ & 1700 & Scatter & $\mathrm{AcAs} \mathrm{Cb}$ & 7500 & Scatter & $\mathrm{CiCsCb}$ & 24000 & 0 & 0 & 1 & Occasional & 0 & Occasional & 0 \\
\hline 29 & Scatter & $\mathrm{Cu} \mathrm{ScCb}$ & 1450 & Scatter & $\mathrm{AcAs} \mathrm{Cb}$ & 9000 & Scatter & $\mathrm{CiCsCb}$ & 26000 & 0 & 1 & 1 & Occasional & 0 & Isolated & 0 \\
\hline 30 & Scatter & $\mathrm{CuScCb}$ & 1450 & Scatter & $\mathrm{AcAs} \mathrm{Cb}$ & 7000 & Scatter & $\mathrm{CiCs} \mathrm{Cb}$ & 24000 & 1 & 1 & 1 & \begin{tabular}{|l|l} 
Isolated \\
\end{tabular} & 26 & \begin{tabular}{|l|} 
Occasional \\
\end{tabular} & 39 \\
\hline 31 & Broken & $\mathrm{Cu} \mathrm{ScCb}$ & 1450 & Scatter & $\mathrm{AcAs} \mathrm{Cb}$ & 7500 & Scatter & $\mathrm{CiCs} \mathrm{Cb}$ & 22000 & 0 & 1 & 1 & Occasional & 0 & Occasional & 0 \\
\hline
\end{tabular}

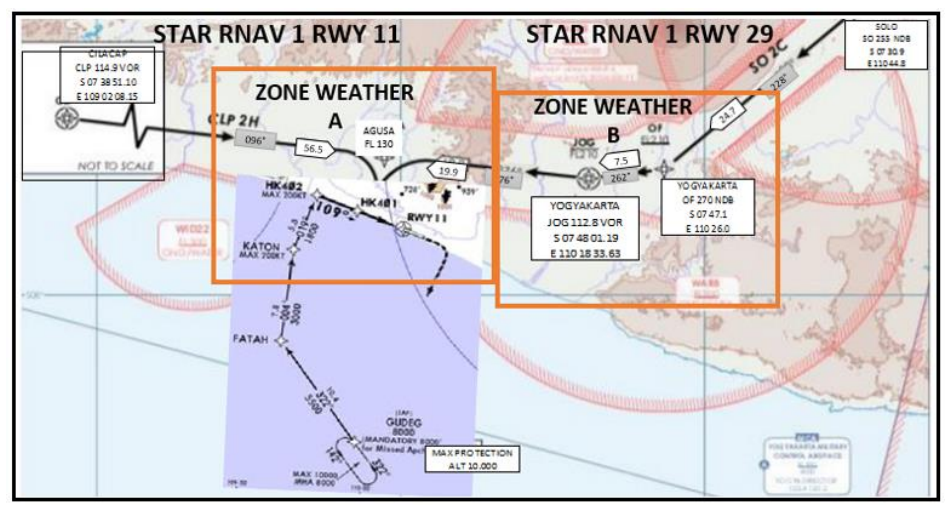

Gambar 2. Weather Area JOG - YIA

\section{Hasil dan Pembahasan}

Dengamatan secara visual saat terbentuknya rain, thunderstorm dan lightning. didapatkan foto dan video rekaman bentukan awan $\mathrm{Cb}$ dan bentukan thunderstorm berikut ini 


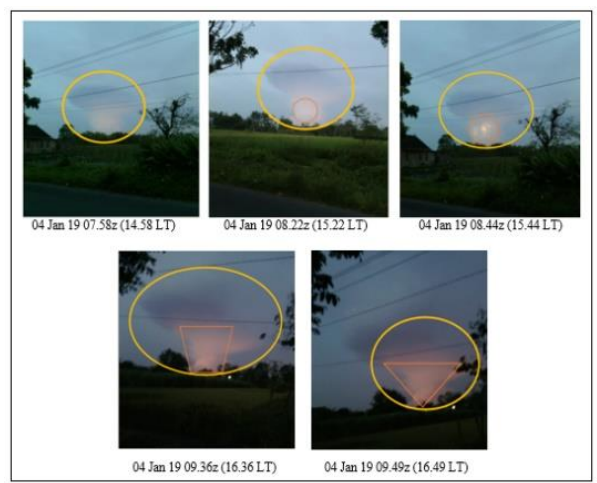

Gambar 3. Light Thunderstorm Area YIA 04 Januari 2019

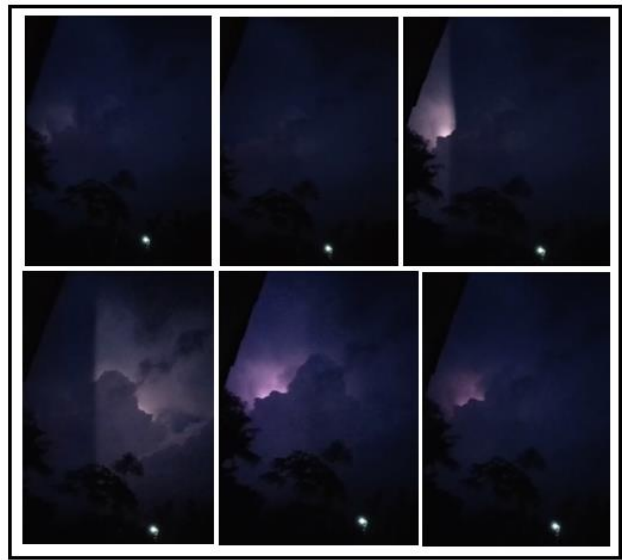

Gambar 4. Video Thunderstorm Rain (TSRA) Area YIA 12 Januari 2019 12.14z (19.14 LT)

\section{A. Penghitungan dan Analisis Cuaca Berdasarkan Data Radiosonde}

Menggunakan data tabel 4 dilakukan penghitungan persentase terhadap kejadian dan didapatkan hasil kejadian thunderstorm (TS) sebanyak 23 kali (30\%), rain (RA) sebanyak 25 kali (32\%), dan icing (ICE) sebanyak 29 kali (38\%). Sedangkan terjadinya awan $\mathrm{Cb}$ dengan kerapatan ISOL sebanyak 16 kali $(51,6 \%)$, OCNL 13 kali (42\%), dan FREQ 2 kali (6,5\%).

Jumlah terjadinya lighting terakumulasi mulai dari Februari 2019 hingga Januari 2019 sebesar nuari 2019 pada area WAHI sebanyak 9328 kali, pada area WAHH sebanyak 6125 kali, seperti terlihat pada tabel berikut ini. 
Tabel 5. Tebel presentasi Weather JOG dan YIA 2019

\begin{tabular}{|c|c|c|c|c|c|c|c|c|c|c|c|c|c|}
\hline \multirow{2}{*}{$\begin{array}{c}\text { Bulan/201 } \\
9\end{array}$} & \multicolumn{5}{|c|}{ Total persentase per bulan } & \multicolumn{6}{|c|}{ Persentase Awan Cumulonimbus } & \multirow{2}{*}{$\begin{array}{c}\begin{array}{l}\text { Weather } \\
\text { Zone A }\end{array} \\
\text { TtI Lighting }\end{array}$} & \multirow{2}{*}{\begin{tabular}{|c|c|}
$\begin{array}{c}\text { Weather } \\
\text { Zone B }\end{array}$ \\
Ttl Lighting \\
\end{tabular}} \\
\hline & TS & & RA & & Ice & & Isol & & Ocnl & & Freqt & & \\
\hline Januari & $23(29,9 \%$ & & $(32,5 \%)$ & & $(37,7 \%)$ & 16 & $51,6 \%)$ & & \begin{tabular}{l|l}
$(41,9 \%)$ \\
\end{tabular} & & $(6,45 \%)$ & 1870 & 1540 \\
\hline Februari & $18(30 \%$ & 19 & $(31,7 \%)$ & 23 & $(38,3 \%)$ & 13 & $46,4 \%)$ & 10 & $(35,7 \%)$ & & $03 \%$ & 1650 & 1320 \\
\hline Maret & $29,2 \%$ & 16 & $(33,3 \%)$ & 18 & $(37,5 \%)$ & 4 & $19 \%)$ & 11 & $(52,4 \%)$ & 6 & $9 \%$ & 1210 & 880 \\
\hline April & $29,6 \%$ & & $(33,3 \%)$ & & $(37 \%)$ & 4 & $13,3 \%)$ & & $(70 \%)$ & 5 & $0,63 \%)$ & 770 & 440 \\
\hline Mei & $3(30 \%$ & & $(30 \%)$ & & $\left(\begin{array}{ll}40 & \%\end{array}\right)$ & 11 & $35,5 \%)$ & 17 & $(54,8 \%)$ & 3 & $0,86 \%$ & 329 & 110 \\
\hline Juni & $5(45,5 \%$ & & $(36,4 \%)$ & & $(18,2 \%)$ & 14 & $46,7 \%)$ & 12 & $(40 \%)$ & 4 & $(1,27 \%)$ & 299 & 100 \\
\hline Juli & $4 \quad(36,4 \%$ & & $(27,3 \%)$ & 4 & $(36,4 \%)$ & 16 & $51,6 \%)$ & 10 & $(32,3 \%)$ & 5 & & 65 & 94 \\
\hline Agustus & $(41,7 \%$ & 3 & $(25 \%)$ & & $(33,3 \%)$ & 16 & $51,6 \%)$ & 11 & $(35,5 \%)$ & 4 & $1,21 \%$ & 316 & 108 \\
\hline September & $140 \%$ & & $(30 \%)$ & & $(30 \%)$ & 12 & $40 \%)$ & 10 & $(33,3 \%)$ & & $5 \% 1$ & & 108 \\
\hline Oktober & \begin{tabular}{l|l}
4 & $36,4 \%$
\end{tabular} & 4 & $(36,4 \%)$ & 3 & $(27,3 \%)$ & 16 & $51,6 \%)$ & 10 & $(32,3 \%)$ & 5 & & 317 & 10 \\
\hline November & $5 \quad 27,8 \%$ & 6 & $(33,3 \%)$ & 7 & $(38,9 \%)$ & 13 & $43,3 \%)$ & 8 & $(26,7 \%)$ & & $(1,59 \%)$ & 550 & 220 \\
\hline Desember & $16(29,1 \%$ & 18 & $(32,7 \%)$ & 21 & $(38,2 \%)$ & 13 & $41,9 \%)$ & 7 & $(22,6 \%)$ & & $(0,76 \%)$ & 1430 & 1100 \\
\hline Mean & $9 \quad 33,8 \%$ & & $(31,8 \%)$ & 11 & $(34,4 \%)$ & 12 & $41,1 \%)$ & 12 & $(39,8 \%)$ & & $(1,6 \%)$ & 9328 & 6125 \\
\hline
\end{tabular}

Dengan menggunakan parameter coordinate batas wilayah udara, kemudian dihitung dna diketahui luas area udara Zona Weather A (area WAHI) sebesar 1.804,896819 $\mathrm{km}^{2}$ dan luas area udara Zona Weather B (area WAHH) sebesar sebesar 659,0940182 $\mathrm{nm}^{2}\left(2.260,629209 \mathrm{~km}^{2}\right)$ maka diketahui nilai kerapatan sambaran petir untuk kedua area zona adalah sebagai berikut

Kerapatan sambaran petir zona WAHI , $\mathrm{d}_{\mathrm{A}}=\frac{9.328}{1.804,896819}$

$\mathrm{d}_{\mathrm{A}}=17,97715$

Berdasarkan tabel tingkat kerapatan sambaran petir dinyatakan dalam kategori "SEDANG".

Kerapatan sambaran petir zoba WAHH $\mathrm{d}_{\mathrm{B}}=\frac{6.125}{2.260,629209}$

$\mathrm{d}_{\mathrm{B}}=9,346163$

Berdasarkan tabel tingkat kerapatan sambaran petir dinyatakan dalam kategori "RENDAH".

B. Penghitungan kestabilan cuaca.

Dengen referensi nilai Showalter Index (SSI), sebagai perbandingan kelembaban lapisan permukaan dan suhu lapisan level bertekanan 500 mbar dari ketinggian 1000 feet hingga 17000 feet pada masing waktu pengamatan kejadian diketahui kondisi kestabilan cuaca dan potensi terjadinya petir untuk masing masing area sebagai berikut:

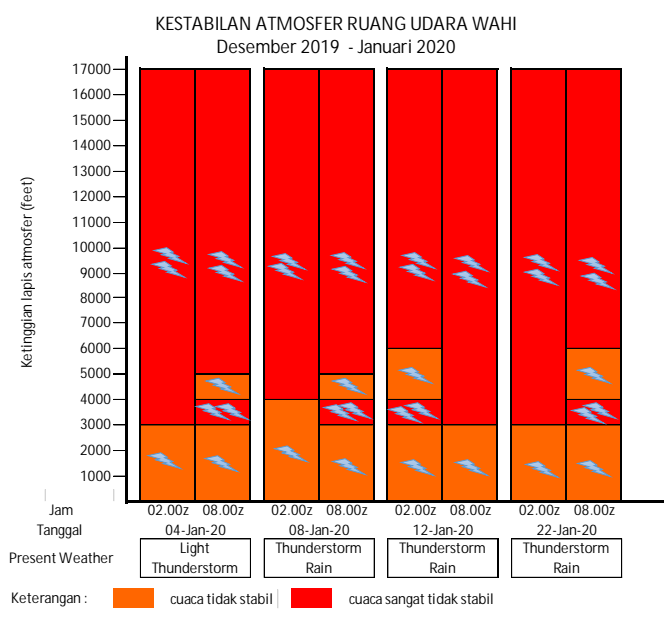

Gambar 5. Kestabilan Atmosfer Ruang Udara WAHI 


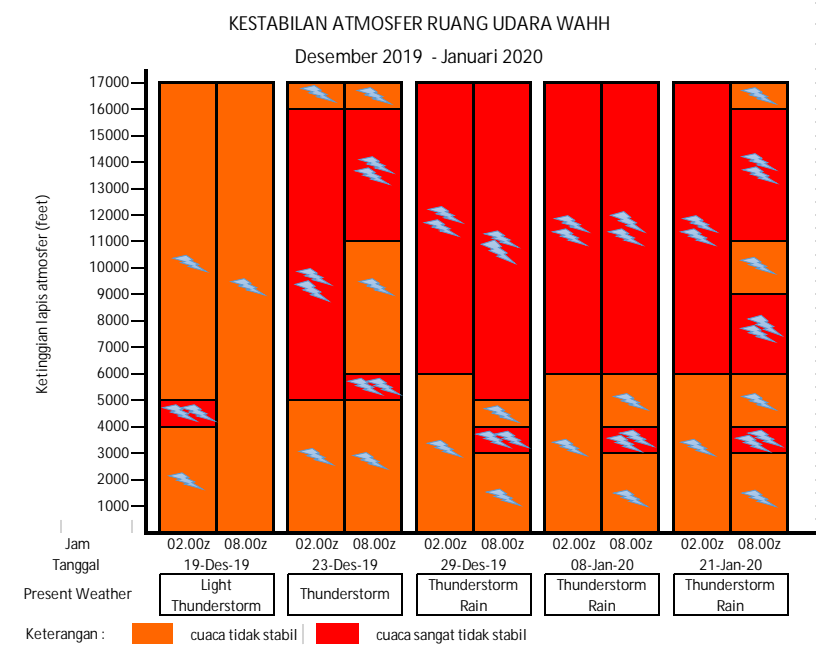

Gambar 6. Kestabilan Atmosfer ruang udara WAHH

C. Penghitungan Lifting Index (LI)

LI merupakan indeks stabilitas yang digunakan untuk menentukan potensi badai.

Dengan menggunakan data rekaman radiosonde dilakukan penghitungan pada kettinggian dimana tercapai tekanan yang mendekati $500 \mathrm{hPa}$, yaitu rata-rata pada ketinggian 15000 feet hingga 16000 feet Area WAHI:

$$
\begin{aligned}
& N P T_{500}=264,59+\left(\frac{500-484,49}{506,94-484,49} x(265,50-264,59)\right) \\
& N P T_{500}=265,22 \mathrm{~K} \\
& N P T p_{500}=269,37+\left(\frac{500-484,49}{506,94-484,49} \times(270,39-269,37)\right) \\
& N P T_{p 500}=270,07 \mathrm{~K} \\
& L I=T_{500}-T_{p_{500}} \\
& \mathrm{LI}=265,22-270,07 \\
& \mathrm{LI}=-4,86
\end{aligned}
$$

Dari tabel LI diketahui kondisi terjadinya thunderstorm dan berpotensi besar terjadinya badai

Area WAHH:

$$
\begin{aligned}
& \mathrm{NP} \mathrm{T}_{500}=260,41+\left(\frac{500-484,49}{506,94-484,49} \times(264,05-260,41)\right) \\
& \mathrm{NP} \mathrm{T}_{500}=262,92 \mathrm{~K} \\
& \mathrm{NP} \mathrm{Tp} \mathrm{p}_{500}=262,60+\left(\frac{500-484,49}{506,94-484,49} \times(266,29-262,60)\right) \\
& \mathrm{NP} \mathrm{Tp}{ }_{500}=265,15 \mathrm{~K}
\end{aligned}
$$




$$
\begin{aligned}
& \mathrm{L}=\mathrm{T}_{500}-\mathrm{T}_{\mathrm{p}_{500}} \\
& \mathrm{LI}=262,92-265,15 \\
& \mathrm{LI}=-2,22
\end{aligned}
$$

Dari tabel LI diketahui kondisi terjadinya thunderstorm dan berpotensi kecil terjadinya badai D. Penghitungan nilai $K$ Index (KI)

KI adalah ukuran potensi badai akibat gerak konvektif, berdasarkan selang suhu vertikal. Indeks menunjukkan terjadinya hujan dengan menghitung tingkat curah hujan.

Dengan menggunakan data rekaman radiosonde dilakukan penghitungan pada kettinggian dimana tercapai tekanan yang mendekati $850 \mathrm{hPa}, 700 \mathrm{hPa}$, dan $500 \mathrm{hPa}$, yaitu pada ketinggian 3000 feet -4000 feet, 7000 feet -8000 feet, dan 15000 feet -16000 feet.

$$
\begin{aligned}
& \text { Area WAHI } \\
& \mathrm{NPt}_{850}=14,82+\left(\frac{850-834,30}{872,95-834,30} \times(17,27-14,82)\right) \\
& \mathrm{NPt}_{850}=15,82^{\circ} \mathrm{C} \\
& \mathrm{NPt}_{500}=-9,10+\left(\frac{500-484,49}{506,94-484,49} \times(-9,10-(-12,74))\right. \\
& \mathrm{NPt}_{500}=-10,23^{\circ} \mathrm{C} \\
& N P t_{d 850}=12,72+\left(\frac{850-834,30}{872,95-834,30} \times(15,07-12,72)\right) \\
& \mathrm{NP}_{\mathrm{d} 850}=13,67^{\circ} \mathrm{C} \\
& N P t_{700}=5,58+\left(\frac{700-696,06}{728,30-696,06} \times(8,15-5,58)\right) \\
& \mathrm{NPt}_{700}=5,89^{\circ} \mathrm{C} \\
& N P t_{d 700}=5,28+\left(\frac{700-696,06}{728,30-696,06} \times(7,96-5,28)\right) \\
& \mathrm{NP} \mathrm{t}_{\mathrm{d} 700}=5,61^{\circ} \mathrm{C} \\
& \mathrm{KI}=\left(\mathrm{t}_{850}-\mathrm{t}_{500}\right)+\mathrm{t}_{\mathrm{d}_{850}}-\left(\mathrm{t}_{700}-\mathrm{t}_{\mathrm{d}_{700}}\right) \\
& \mathrm{KI}=(15,82-(-10,23)+13,67-(5,89-5,61) \\
& \mathrm{KI}=39,42
\end{aligned}
$$

Dari tabel KI menunjukkan bahwa cuaca saat itu berpeluang terjadinya konveksi sedang, curah hujan sedang dan kemungkinan terjadinya badai.

\section{Area WAHH}

$$
\begin{aligned}
& \mathrm{NPt}_{850}=16,60+\left(\frac{850-834,30}{872,95-834,30} \times(18,81-16,60)\right) \\
& \mathrm{NPt}_{850}=17,5^{\circ} \mathrm{C} \\
& \mathrm{NPt}_{500}=-7,65+\left(\frac{500-484,49}{506,94-484,49} \times(-7,65-(-8,56))\right. \\
& \mathrm{NPt}_{500}=-7,93^{\circ} \mathrm{C} \\
& \mathrm{NPt}_{\mathrm{d} 850}=14,50+\left(\frac{850-834,30}{872,95-834,30} \times(16,61-14,50)\right) \\
& \mathrm{NPt} \mathrm{d}_{850}=15,36^{\circ} \mathrm{C}
\end{aligned}
$$




$$
\begin{aligned}
& \mathrm{NPt}_{700}=7,84+\left(\frac{700-696,06}{728,30-696,06} \times(9,94-7,84)\right) \\
& \mathrm{NPt}_{700}=8,10^{\circ} \mathrm{C} \\
& \mathrm{NP} \mathrm{td}_{700}=7,54+\left(\frac{700-696,06}{728,30-696,06} \times(9,75-7,54)\right) \\
& \mathrm{NPt} \mathrm{d}_{700}=7,81^{\circ} \mathrm{C} \\
& \mathrm{KI}=\left(\mathrm{t}_{850}-\mathrm{t}_{500}\right)+\mathrm{t}_{\mathrm{d}_{850}}-\left(\mathrm{t}_{700}-\mathrm{t}_{\mathrm{d}_{700}}\right) \\
& \mathrm{KI}=(17,50-(-7,93)+15,36-(8,10-7,81) \\
& \mathrm{KI}=40,49
\end{aligned}
$$

Dari tabel KI menunjukkan bahwa berpeluang terjadinya konveksi tinggi, curah hujan tinggi dan kemungkinan terjadinya badai.

\section{E. Penghitungan nilai Total - Totals Index (TTI)}

TTI dihitung untuk mengukur potensi pengembangan badai dan tingkat kehebatan badai. Dengan menggunakan data rekaman radiosonde dilakukan penghitungan pada kettinggian dimana tercapai tekanan yang mendekati $850 \mathrm{hPa}$, dan $500 \mathrm{hPa}$, yaitu pada ketinggian 3000 feet - 4000 feet, dan 15000 feet -16000 feet.

\section{Area WAHI}

$$
\begin{aligned}
& \text { TTI }=(17,50-(-4,62))+(15,36-(-4,62)) \\
& T T I=48,71
\end{aligned}
$$

Dari tabel TTI menunjukkan bahwa cuaca saat itu berpeluang terjadinya konveksi sedang, curah hujan sedang dan kemungkinan terjadinya badai $75 \%$.

\section{Area WAHH \\ TTI $=(15,82-(-10,23))+(13,67-(-10,23))$ \\ $\mathrm{TTI}=49,94$}

Dari tabel TTI menunjukkan bahwa cuaca saat itu berpeluang terjadinya konveksi sedang, curah hujan sedang dan kemungkinan terjadinya badai $75 \%$.

F. Penghitungan nilai SWEAT Index.

Index SWEAT digunakan untuk memperkirakan potensi cuaca buruk, tetapi tetap memperhitungkan adanya mekanisme pemicu lain yang dapat mempengaruhi terjadinya cuaca buruk. Nilai indeks SWEAT yang rendah menandakan tidak adanya cuaca buruk, demikian sebaliknya. Dengan menggunakan data rekaman radiosonde dilakukan penghitungan pada kettinggian dimana tercapai tekanan yang mendekati $850 \mathrm{hPa}$, dan $500 \mathrm{hPa}$, yaitu pada ketinggian 3000 feet -4000 feet, dan 15000 feet -16000 feet.

Area WAHI

$$
\begin{aligned}
& \text { NP Crs } 850=20+\left(\frac{850-834,30}{872,95-834,30} \times(26-20)\right) \\
& \text { NP Crs } 850=22,44^{\circ} \\
& \text { sehingga nilai s }=\sin 22,44=0,381 \\
& \text { SWEAT }=(12 \times 15,36)+20(48,71-49)+(2 \times 21,81+18,93+125(0,381+0,2) \\
& \text { SWEAT }=313,8097 \\
& \text { Dari tabel SWEAT menunjukkan cuaca saat itu dalam kondisi buruk. }
\end{aligned}
$$


Area WAHH

$\mathrm{NP} \operatorname{Crs} 850=24+\left(\frac{850-834,30}{872,95-834,30} \times(26-24)\right)$

$\mathrm{NP}$ Crs $850=22,81^{0}$

sehingga nilai $\mathrm{s}=\sin 22,81=0,419$

SWEAT $=(12 \times 13,67)+20(49,94-49)+(2 \times 22,22+21,24+125(0,419+0,2)$

SWEAT $=325,9522$

Dari tabel SWEAT menunjukkan cuaca saat itu dalam kondisi buruk.

Dari penelitian yang dilakukan dapat disimpulkan bahwa

a. Cuaca dengan tingkat sambaran petir di area Yogyakarta International Airport adalah $\left(\mathrm{d}_{\mathrm{A}}\right.$ $=17,97715$ ) dalam kategori "SEDANG" dan di area Adisutjipto International Airport selama tahun 2019 adalah $\left(\mathrm{d}_{\mathrm{B}}=9,346163\right)$ dalam kategori "RENDAH".

Dengen referensi nilai Showalter Index (SSI), sebagai perbandingan kelembaban lapisan permukaan dan suhu lapisan level bertekanan 500 mbar dari ketinggian 1000 feet hingga 17000 feet pada masing waktu pengamatan kejadian diketahui kondisi kestabilan cuaca dan potensi terjadinya petir untuk masing masing area sebagai berikut:

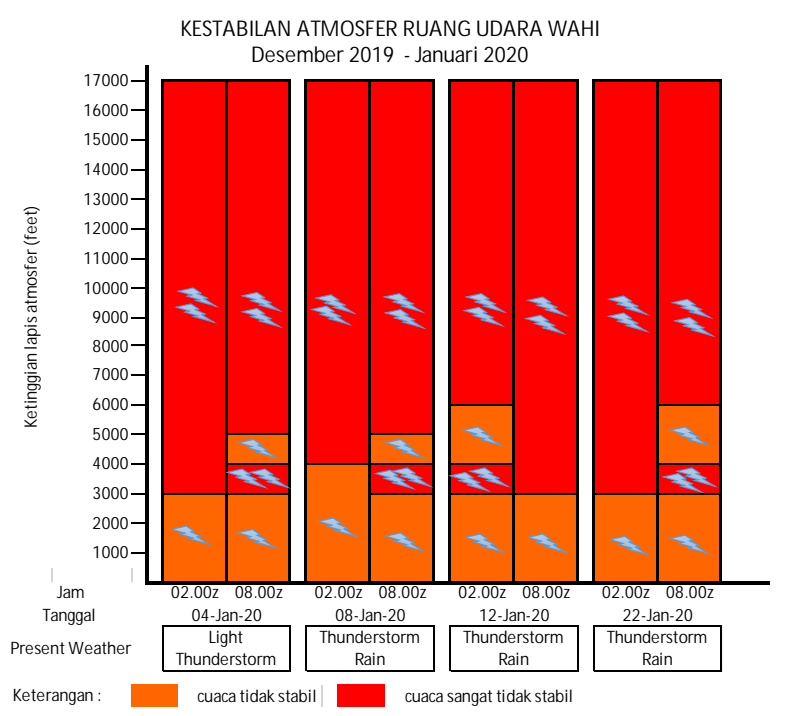

Gambar 7. Kestabilan Atmosfer Ruang Udara WAHI 


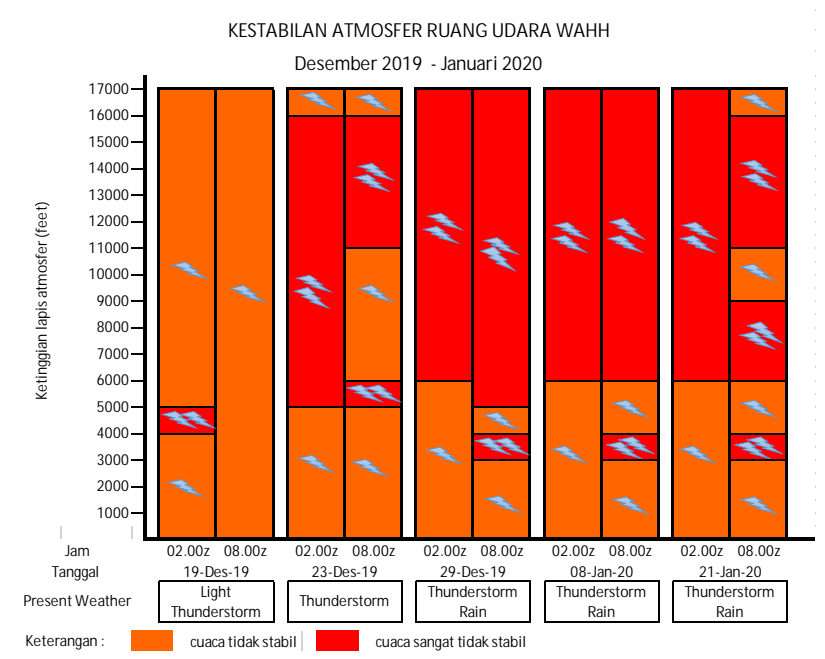

Gambar 8. Kestabilan Atmosfer ruang udara WAHH

b. Penghitungan Lifting Index (LI)

LI merupakan indeks stabilitas yang digunakan untuk menentukan potensi badai.

Dengan menggunakan data rekaman radiosonde dilakukan penghitungan pada kettinggian dimana tercapai tekanan yang mendekati $500 \mathrm{hPa}$, yaitu rata-rata pada ketinggian 15000 feet hingga 16000 feet

Area WAHI:

$$
\begin{aligned}
& N P T_{500}=264,59+\left(\frac{500-484,49}{506,94-484,49} x(265,50-264,59)\right) \\
& N P T_{500}=265,22 \mathrm{~K} \\
& N P T p_{500}=269,37+\left(\frac{500-484,49}{506,94-484,49} x(270,39-269,37)\right) \\
& N P T_{p 500}=270,07 \mathrm{~K} \\
& L I=T_{500}-T_{p_{500}} \\
& \mathrm{LI}=265,22-270,07 \\
& \mathrm{LI}=-4,86
\end{aligned}
$$

Dari tabel LI diketahui kondisi terjadinya thunderstorm dan berpotensi besar terjadinya badai

Area WAHH:

$$
\begin{aligned}
& \mathrm{NP} \mathrm{T}_{500}=260,41+\left(\frac{500-484,49}{506,94-484,49} \times(264,05-260,41)\right) \\
& \mathrm{NP} \mathrm{T}_{500}=262,92 \mathrm{~K} \\
& \mathrm{NP} \mathrm{Tp}_{500}=262,60+\left(\frac{500-484,49}{506,94-484,49} \times(266,29-262,60)\right) \\
& \mathrm{NP} \mathrm{Tp}_{500}=265,15 \mathrm{~K}
\end{aligned}
$$


$\mathrm{L}=\mathrm{T}_{500}-\mathrm{T}_{\mathrm{p}_{500}}$
$\mathrm{LI}=262,92-265,15$
$\mathrm{LI}=-2,22$

Dari tabel LI diketahui kondisi terjadinya thunderstorm dan berpotensi kecil terjadinya badai

c. Penghitungan nilai $K$ Index (KI)

KI adalah ukuran potensi badai akibat gerak konvektif, berdasarkan selang suhu vertikal. Indeks menunjukkan terjadinya hujan dengan menghitung tingkat curah hujan.

Dengan menggunakan data rekaman radiosonde dilakukan penghitungan pada kettinggian dimana tercapai tekanan yang mendekati $850 \mathrm{hPa}, 700 \mathrm{hPa}$, dan $500 \mathrm{hPa}$, yaitu pada ketinggian 3000 feet -4000 feet, 7000 feet -8000 feet, dan 15000 feet -16000 feet.

Area WAHI

$$
\begin{aligned}
& \mathrm{NPt}_{850}=14,82+\left(\frac{850-834,30}{872,95-834,30} \times(17,27-14,82)\right) \\
& \mathrm{NPt}_{850}=15,82^{\circ} \mathrm{C} \\
& \mathrm{NPt}_{500}=-9,10+\left(\frac{500-484,49}{506,94-484,49} \times(-9,10-(-12,74))\right. \\
& \mathrm{NPt}_{500}=-10,23^{\circ} \mathrm{C} \\
& N P t_{d 850}=12,72+\left(\frac{850-834,30}{872,95-834,30} \times(15,07-12,72)\right) \\
& \mathrm{NPt}_{\mathrm{d} 850}=13,67^{\circ} \mathrm{C} \\
& \mathrm{NPt}_{700}=5,58+\left(\frac{700-696,06}{728,30-696,06} \times(8,15-5,58)\right) \\
& \mathrm{NPt}_{700}=5,89^{\circ} \mathrm{C} \\
& N P t_{d 700}=5,28+\left(\frac{700-696,06}{728,30-696,06} \times(7,96-5,28)\right) \\
& \mathrm{NPt} \mathrm{t}_{\mathrm{d} 700}=5,61^{\circ} \mathrm{C} \\
& \mathrm{KI}=\left(\mathrm{t}_{850}-\mathrm{t}_{500}\right)+\mathrm{t}_{\mathrm{d}_{850}}-\left(\mathrm{t}_{700}-\mathrm{t}_{\mathrm{d}_{700}}\right) \\
& \mathrm{KI}=(15,82-(-10,23)+13,67-(5,89-5,61) \\
& \mathrm{KI}=39,42
\end{aligned}
$$

Dari tabel KI menunjukkan bahwa cuaca saat itu berpeluang terjadinya konveksi sedang, curah hujan sedang dan kemungkinan terjadinya badai.

Area WAHH

$$
\begin{aligned}
& \mathrm{NPt}_{850}=16,60+\left(\frac{850-834,30}{872,95-834,30} \times(18,81-16,60)\right) \\
& \mathrm{NPt}_{850}=17,5^{\circ} \mathrm{C} \\
& \mathrm{NPt}_{500}=-7,65+\left(\frac{500-484,49}{506,94-484,49} \times(-7,65-(-8,56))\right. \\
& \mathrm{NPt}_{500}=-7,93^{0} \mathrm{C} \\
& \mathrm{NPt}_{\mathrm{d} 850}=14,50+\left(\frac{850-834,30}{872,95-834,30} \times(16,61-14,50)\right)
\end{aligned}
$$




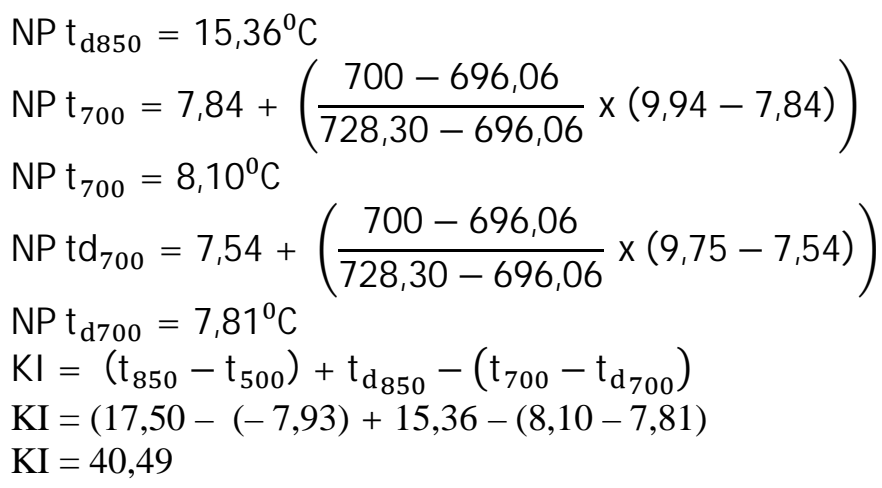

Dari tabel KI menunjukkan bahwa berpeluang terjadinya konveksi tinggi, curah hujan tinggi dan kemungkinan terjadinya badai.

d. Penghitungan nilai Total - Totals Index (TTI)

TTI dihitung untuk mengukur potensi pengembangan badai dan tingkat kehebatan badai.

Dengan menggunakan data rekaman radiosonde dilakukan penghitungan pada kettinggian dimana tercapai tekanan yang mendekati $850 \mathrm{hPa}$, dan $500 \mathrm{hPa}$, yaitu pada ketinggian 3000 feet -4000 feet, dan 15000 feet -16000 feet.

Area WAHI

$\mathrm{TTI}=(17,50-(-4,62))+(15,36-(-4,62))$

$T T I=48,71$

Dari tabel TTI menunjukkan bahwa cuaca saat itu berpeluang terjadinya konveksi sedang, curah hujan sedang dan kemungkinan terjadinya badai $75 \%$.

Area WAHH

TTI $=(15,82-(-10,23))+(13,67-(-10,23))$

TTI $=49,94$

Dari tabel TTI menunjukkan bahwa cuaca saat itu berpeluang terjadinya konveksi sedang, curah hujan sedang dan kemungkinan terjadinya badai $75 \%$.

e. Penghitungan nilai SWEAT Index.

Index SWEAT digunakan untuk memperkirakan potensi cuaca buruk, tetapi tetap memperhitungkan adanya mekanisme pemicu lain yang dapat mempengaruhi terjadinya cuaca buruk.

Nilai indeks SWEAT yang rendah menandakan tidak adanya cuaca buruk, demikian sebaliknya. Dengan menggunakan data rekaman radiosonde dilakukan penghitungan pada kettinggian dimana tercapai tekanan yang mendekati $850 \mathrm{hPa}$, dan $500 \mathrm{hPa}$, yaitu pada ketinggian 3000 feet -4000 feet, dan 15000 feet -16000 feet.

Area WAHI

$$
\begin{aligned}
& \text { NP Crs } 850=20+\left(\frac{850-834,30}{872,95-834,30} \times(26-20)\right) \\
& \text { NP Crs } 850=22,44^{0} \\
& \text { sehingga nilai s }=\sin 22,44=0,381 \\
& \text { SWEAT }=(12 \times 15,36)+20(48,71-49)+(2 \times 21,81+18,93+125(0,381+0,2) \\
& \text { SWEAT }=313,8097
\end{aligned}
$$


Dari tabel SWEAT menunjukkan cuaca saat itu dalam kondisi buruk.

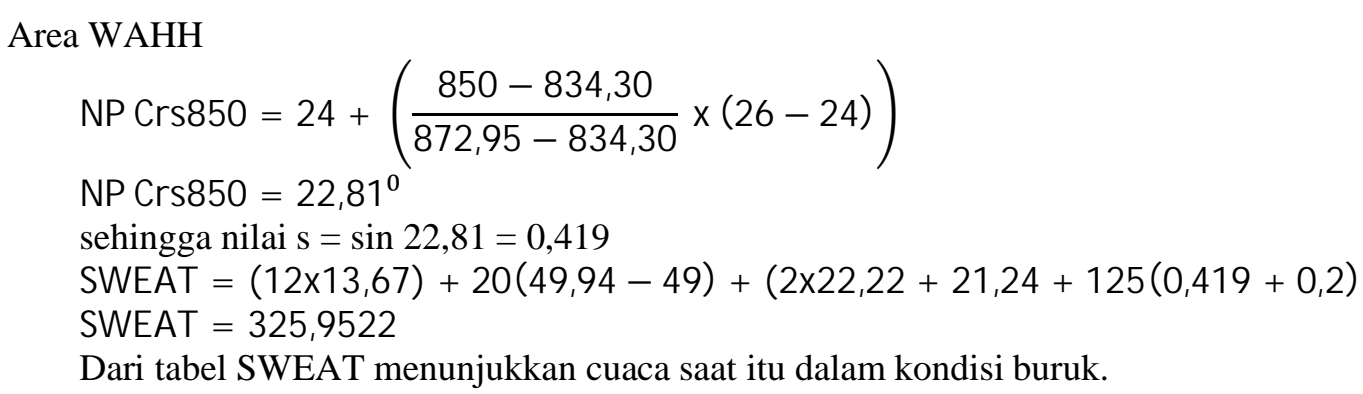

\section{Kesimpulan}

Cuaca dengan tingkat sambaran petir di area Yogyakarta International Airport adalah $\left(\mathrm{d}_{\mathrm{A}}=17,97715\right)$ dalam kategori "SEDANG" dan di area Adisutjipto International Airport selama tahun 2019 adalah $\left(\mathrm{d}_{\mathrm{B}}\right.$ =9,346163) dalam kategori "RENDAH". Dilihat dari tingkat stabilan cuaca ruang udara WAHI berpeluang terjadi heavy rain, thunderstom serta lightning hingga $75 \%$ yang cenderung lebih stabil dan lama pada ketinggian mulai dari 3000 feet dan diatasnya sementara ruang udara WAHH berpeluang terjadi heavy rain, thunderstom serta lightning hingga $75 \%$ dan dengan tingkat keburukan cuaca yang tidak stabil.

Pada area WAHI nilai-nilai indek yang didapatkan adalah $\mathrm{LI}=-4,86, \mathrm{KI}=39,42$, TTI $=48,71$, dan SWEAT $=313,8097$. Sementara pada area WAHH nilai-nilai indek yang didapatkan adalah $L I=-2,22$, $\mathrm{KI}=40,49$, TTI $=49.94$ dan SWEAT $=325,9522$. Secara umum ruang udara WAHI berpeluang lebih besar terjadinya badai thunderstorm dan lightning dengan kestabilan yang lebih besar dibandingkan dengan area WAHH.

\section{Ucapan Terima kasih}

Ucapan terima-kasih disampaikan kepada P3M Sekolah Tinggi Teknologin Adisutjipto yang telah berperan dalam memberikan bantuan dana untuk pelaksanaan penelitian ini

\section{Daftar Pustaka}

[1] AMS Glossary of Meteorology, 1990

[2] Budiarti M. Muslim \& Ilhamsyah, 2015. Studi Indeks Stabilitas Udara Terhadap Prediksi Badai Guntur

[3] Djazim Syaifullah, 2010. Potensi Atmosfer Dalam pembentukan Awan Konvektif Pada Pelaksanaan Teknologi Modifikasi Cuaca di Das Kotopanjang dan Das Singkarak

[4] Djuric D, 1994. Weather Analysis, Prentice-Hall Inc.

[5] Lukito Indro,2017. Diktat Meteorology penerbangan. Merpati Training Center.

[6] Minder JRPW dan ID Lundquist, 2010. Surface Temperature Lapse Rate Over Complex Terrain.

[7] Niviani RM, 2016. Analisis Potensi Badai Guntur dengan Metode Rapid Miner dan Fuzzy Logic.

[8] Roger, 1979, A Short Course In Cloud Physic, $2^{\text {nd }}$ edition, Pergamon Press.

[9] Salby,1996. Fundamental of Atmospheric Physic, Volume 61' Academic Press, Sandiego

[10] Simson Garfinkel, 2011. The Cloud Imperative - Technology review (MIT)

[11] Stull BR, 1988. An Introduction to Boundary Layer Meteorology

[12] Tonny Gunawan dan Lestari Naomi Lydia Pandiangan, 2014. Kajian Tingkat Sambaran Petir balai Besar Meteorologi Klimatologi dan Geofisika 
[13] Ulfah Kurnia, Didik Sugianto, Rahmat Urdani, 2017. Analisis Potensi Thunderstorm di Suntan Iskandar Muda Menggunakan Metode SWEAT

[14] Wallace Jhon, and Peter V Hobbs, 1977. Atmosphecric Science and Introduction Survey. Academic Press, New York

[15] Sensirion. 2007. SHT1x Humidity and Temperature Sensor.

[16] Pramana P Agusto., 2012, Rancang Bangun Alat Pengukur Suhu, Kelembapan dan Tekanan Udara . Akademi Meteorologi dan Geofisika Jakarta

[17] Toruan, Kanton L., 2009. Automatic Weather Station (AWS) Berbasis Mikrokontroler Tesis, Program Pasca Sarjana Fakultas MIPA UI, Depok

[18] Edward Aguado, and James E.burt. Understanding Weather and Climate. New Jersey : Pearson Prentice Hall, 2017 